\title{
Price Controls and Consumer Surplus
}

the latest version of this paper, and related material, will be at

www.paulklemperer.org

\author{
Jeremy Bulow \\ Stanford University \\ Graduate School of Business \\ Stanford, CA 94305-5015, USA \\ email: jbulow@stanford.edu \\ and \\ Paul Klemperer \\ Nuffield College, Oxford University \\ Oxford OX1 1NF, England \\ Int Tel: +447776230123 \\ email: paul.klemperer@economics.ox.ac.uk
}

July 2009

\begin{abstract}
:
The condition for when a price control increases consumer welfare in perfect competition is tighter than often realised. When demand is linear, a small restriction on price only increases consumer surplus if the elasticity of demand exceeds the elasticity of supply; with log-linear or constant-elasticity, demand consumers are always hurt by price controls. The results are best understood - and can be related to monopoly-theory results - using the fact that consumer surplus equals the area between the demand curve and the industry marginal-revenue curve.
\end{abstract}

Acknowledgments to be completed later 
Consider a competitive industry with a completely inelastic supply curve. Will consumer surplus be increased by price controls that are "sufficiently small"? Perhaps surprisingly, there are significant conditions under which even this mild case for price controls fails, because of the misallocation caused by rationing when price does not clear the market.

In the very short run it is clear that a reduction in apartment rents, say, will increase consumer surplus. Supply is likely to be inelastic, and units are allocated to the same people who had them without the price controls, so the price control must primarily transfer wealth from landlords to tenants. But over the longer run there will be misallocation, even with inelastic supply. In other markets, such as the market for gasoline, misallocation will be significant immediately. ${ }^{1}$ Of course, as supply falls in response to lower prices consumer surplus will fall further.

Say that output is allocated randomly amongst those willing to pay more than the fixed price. Then we show that any calculation purporting to show that price controls benefit consumers, necessarily depends on assumptions about the functional form of demand. For example, price controls always reduce consumer surplus with constant elasticity demand, regardless of the assumed or estimated parameters of the demand equation. While tight bounds can be derived for conditions under which consumer surplus is certain to decline because of a price control, even if supply is completely inelastic, perhaps the larger point is that it is not really possible to show persuasively that a price control has increased consumer surplus - this will typically be assumed (or assumed away) through a choice of demand specification.

Our results apply to competitive models ${ }^{2}$ in which individual consumers are randomly chosen to either have their demand satisfied in full or not at all. Rental housing is one example; natural gas, where consumers who are supplied receive all they want but not all who wish to be served are supplied, is another example. If consumers have downward sloping demand and rationing is imposed the results may or may not apply depending on the efficiency of the rationing scheme. If, for example, individuals each have identical downward sloping demand curves, a rationing scheme would efficiently reduce demand and so, when combined with a price control and sufficiently inelastic supply, will increase consumer surplus. On the other hand, if consumers who would

\footnotetext{
${ }^{1}$ We put aside the possible gains from resale markets, which will increase consumer surplus to the extent that allocative efficiencies are not offset by transactions costs.

${ }^{2}$ It is well understood that imposing a price control on a monopolist can increase quantity, consumer surplus, and efficiency.
} 
buy the most in an uncontrolled market also have the highest average values per unit then per capita rationing may be worse than random allocation. Regarding housing, Glaeser and Luttmer (1997) argue the allocation of rental units may be worse than random if transient residents, who are unlikely to secure rent-controlled units, have a higher than average willingness to pay. ${ }^{3}$

It has long been understood that the losses from price controls include not just the foregone supply, but also the inefficiency from the fact that the rationed output may not be allocated to the highest-value consumers. For example, Friedman and Stigler (1946), and Glaeser and Luttmer's (2003) well-known study of apartment occupancy in New York City, emphasise these allocative losses from rent controls; Lott (1990), Luttmer (2007), and Palda (2000) discuss these costs in the context of minimum-wage legislation; and MacAvoy and Pindyck (1975), Braeutigam and Hubbard (1986), and Davis and Killian's (2008) careful recent study, analyse the costs of restricting new potential consumers' access to the natural gas market. ${ }^{4}$

A clear exposition of the standard theoretical analysis of these "allocative costs" is in Viscusi, Harrington, and Vernon (2005). But quantitative estimates of welfare losses in the literature mostly depend upon functionalform assumptions. Furthermore, most papers have focused on the total social losses (that is, the sum of consumer and producer surplus). There has been much less discussion of whether consumers are likely to lose on net from price controls, that is, whether the allocative costs that rationing creates, combined with the deadweight losses to consumers, are likely to exceed the rents that price controls transfer from producers to consumers.

\section{The Model}

Consider an industry with a demand curve $D(p)$ and a supply curve $S(p)$, with $D^{\prime}(p) \leq 0$, and $S^{\prime}(p) \geqslant 0$ (that is, no "backward-bending" supply).

\footnotetext{
${ }^{3}$ Our analysis assumes consumers do not dissipate surplus competing for the rationed good. If, for example, the good is allocated by a queueing system, the time spent waiting in line will rise to clear the market. If supply is inelastic, then whether consumer surplus rises or falls depends on whether consumers' gains from the price reduction are larger or smaller than the efficiency losses created by both the waiting costs incurred and the reallocation of goods to consumers with low values but low waiting costs. If low-value, low-waiting cost buyers have lower incomes, there may be distributional gains from the price control that our analysis ignores.

${ }^{4}$ Relatedly, Grafton and Ward (2008) suggest there may be substantial losses when rationing restricts individuals from making their highest-value uses of the rationed good; they study the market for water in Sydney, Australia.
} 
Assume that if a regulator sets a price $p$ below the market clearing level then demand is randomly allocated among consumers with a value greater than $p .^{5}$ So consumer surplus at the controlled price, $C S(p)$, equals consumer surplus if the market cleared at $p$ (that is, $\int_{p}^{\infty} D(x) d x^{6}$ ) times the ratio of supply to demand, $S(p) / D(p)$ :

$$
C S(p)=\frac{S(p)}{D(p)}\left[\int_{p}^{\infty} D(x) d x\right] .
$$

Differentiating with respect to a small decrease in price $-d p$ yields

$$
-C S^{\prime}(p)=S(p)-S^{\prime}(p) \frac{\int_{p}^{\infty} D(x) d x}{D(p)}+D^{\prime}(p) \frac{S(p)}{D^{2}(p)}\left[\int_{p}^{\infty} D(x) d x\right]
$$

That is, the total change in consumer welfare is the sum of three effects. First, the reduced price paid by the total number of buyers, $S(p)$. Second, the reduction in market supply, $S^{\prime}(p)$, times the average surplus of the old buyers, $\int_{p}^{\infty} D(x) d x / D(p)$. Third, the number of new buyers who will displace old buyers - that is, the number of new buyers, $-D^{\prime}(p)$, times the fraction who will be served, $S(p) / D(p)$ - times the negative of the average surplus of the old buyers (since the new buyers receive no surplus while the displaced buyers received the average).

Now if demand $D(p)$ is log-convex then, since also $D(\infty)=0, \int_{p}^{\infty} D(x) d x$ is also log-convex, ${ }^{7}$ that is, $\left(-D^{\prime}(p)\right)\left(\int_{p}^{\infty} D(x) d x\right) \geqslant(D(p))^{2}$. So the loss from the last term in (2) exceeds the gain from the first term. That is, the reduction in consumers' average values exceeds the reduction in the price they pay. It follows that any price reduction reduces consumers' welfare because the middle term in (2) - the decrease in supply - only exacerbates their loss. So for any sufficiently "fat-tailed" demand, ${ }^{8}$ for example, with log-linear, or constant-elasticity, demand, consumers are always hurt by price controls.

\footnotetext{
${ }^{5}$ This is the standard assumption made in, for example, Viscusi, Harrington, and Vernon (2005).

${ }^{6} \mathrm{We}$ assume this integral is finite. Sufficient conditions are that demand is finite at $p$, and is elastic (elasticity of demand $\eta \leq-1-\varepsilon$, for some strictly positive constant $\varepsilon$ ) for all prices above some finite price. So, for example, constant elasticity demand with inelastic demand $(\eta \geq-1)$ is ruled out.

${ }^{7}$ See, for example, Bagnoli and Bergstrom (2005, Theorem 4). Earlier references on the role of log-curvature are Prékopa (1971) and An (1998).

${ }^{8}$ Even for goods for which individual demand is "thin-tailed", aggregate consumer demand may be fat-tailed when income distribution is very unequal.
} 


\section{MR Interpretation}

Using the fact that consumer surplus equals the area between the demand curve and the marginal revenue curve (because the area under the $M R$ curve equals total sellers' revenues), we can rewrite (1) as

$$
C S(p)=\frac{S(p)}{D(p)} \int_{p}^{\infty}-D^{\prime}(v)[v-M R(v)] d v
$$

since $-D^{\prime}(v)$ is the density of consumers with a value of $v$.

This allows us to rewrite (2) as $^{9}$

$$
\begin{aligned}
-C S^{\prime}(p)= & -D^{\prime}(p) \frac{S(p)}{D(p)}[p-M R(p)] \\
& +\left[D^{\prime}(p) \frac{S(p)}{D(p)}-S^{\prime}(p)\right]\left[\frac{\int_{p}^{\infty} D^{\prime}(v)[v-M R(v)] d v}{D(p)}\right]
\end{aligned}
$$

Formula (4) can be interpreted by recognizing that $[p-M R(p)]$ is the increment in consumer surplus in an open market, caused by a price reduction that leads to a one unit increase in quantity, while $\left[\frac{\int_{p}^{\infty} D^{\prime}(v)[v-M R(v)] d v}{D(p)}\right]$ is the average consumer surplus. So the change in consumer surplus due to the price control is given by the number of new customers, $-D^{\prime}(p)$, times the probability that they will be served, $S(p) / D(p)$, times the marginal consumer surplus, less the reduction in number of existing consumers who will be served (the number of new customers who displace old ones plus any supply effect) times the average consumer surplus of the existing customers.

In words, the change in consumer surplus due to a small price cut is

$$
\begin{aligned}
\Delta \mathrm{CS}= & \left((\Delta \text { Demand })\left(\frac{\text { Supply }}{\text { Demand }}\right)\right) \cdot(\text { M arg inal CS }) \\
& -\left((\Delta \text { Demand })\left(\frac{\text { Supply }}{\text { Demand }}\right)+(\Delta \text { Supply })\right) \cdot(\text { Average CS })
\end{aligned}
$$

Since $\Delta$ Supply $\leq 0$ the equation implies that a sufficient condition for consumer surplus to decline is that Average $C S>$ Marginal $C S .^{10}$

\footnotetext{
${ }^{9}$ We can derive (4) directly from (2) using $M R(p) \equiv p+D(p) / D^{\prime}(p)$ (the derivative of total industry revenue $p D(p)$ with respect to quantity $D(p)$ in an uncontrolled market with price $p$ ).

${ }^{10}$ This is analagous to Spence's (1975) result that whether a profit-maximizing monopolist over- or under-provides quality depends whether the marginal value of quality is higher for the marginal or the average consumer.
} 
Figure 1 provides a simple graphical analysis for a discrete price change assuming no supply effect. When price is reduced from the market level $P^{\text {Market }}$ to the controlled level $P^{\text {Control }}$, demand increases from $D\left(P^{\text {Market }}\right)$ to $D\left(P^{\text {Control }}\right)$. Were the decline in price due to a shift in the supply curve, consumer surplus would increase from $C S^{\text {Market }}$ to $C S^{\text {Market }}+X C S$, the area between the demand and marginal revenue curves in the range of $D\left(P^{\text {Market }}\right)$ to $D\left(P^{\text {Control }}\right) \cdot{ }^{11}$ But with price controls there is an offsetting loss of consumer surplus because supply will at best remain constant. Therefore, while the lower price increases consumer surplus by the average height of $X C S$ times the number of new customers served, there are at least an equal number of consumers who are displaced by the controls. Those consumers had received an average consumer surplus equal to the average height of $C S^{\text {Market }}$. For the demand curve pictured in Figure $1^{12}$ the difference between the demand and marginal revenue curves is declining at all but very small quantities, and so the average height of $C S^{\text {Market }}$ is greater than the average height of $X C S$. So the loss in consumer surplus due to unfilled demand exceeds the gain due to the lower price, even before considering any decline in supply.

\section{Relationship to Monopoly Results}

Our condition also has simple monopoly-theory interpretations. Specifically, a small tightening of the price control always reduces consumer surplus if the constant-marginal-cost monopolist that would set the same price on the demand curve (as the current price control) would generate greater (total) consumer surplus than (total) profits. Since the monopolist sets $M R(p)=$ $M C=A C$, the profit per unit of a constant-marginal-cost monopolist is equal to $p-M R(p)$, which is just marginal CS. So equation (5) tells us that if marginal CS $=$ average profit is less than average CS, then $\Delta \mathrm{CS}$ will be negative when we tighten a price control.

It also follows that any price control reduces consumer surplus for any demand curve on which a constant-marginal-cost monopolist would always pass through more than $100 \%$ of any (marginal) tax or cost increase. Perhaps the best way to see this is to note that a monopolist's pass-through rate

\footnotetext{
${ }^{11}$ Of course little of the incremental consumer surplus goes to the new purchasers; the area $X C S$ is the amount of surplus gained by all consumers when price falls by enough to attract $D\left(P^{\text {Control }}\right)-D\left(P^{\text {Market }}\right)$ additional purchasers.

${ }^{12}$ The demand curve graphed is $D(p)=\left(\frac{p-3}{80}\right)^{-3 / 2}-1$ for $3<p \leq 83$.
} 
exceeds 1 if and only if demand is steeper than marginal revenue (because pass-through rate $=\frac{d p}{d M C}=\frac{d p}{d M R}($ using $\left.M R=M C)=\frac{\text { slope of demand }}{\text { slope of } M R}{ }^{13}\right)$ - and it is easy to see from Figure 1 that if the slope of the demand curve is steeper than the slope of the MR curve, then marginal consumer surplus is less than average consumer surplus and so consumer surplus falls due to the price control. ${ }^{14}$ Of course, this result also follows from our earlier result that a price control reduces consumer surplus on any log-convex demand, together with the standard result that a constant-marginal-cost monopolist's (or Cournot oligopoly's) pass-through exceeds 100\% if and only if demand is logconvex. ${ }^{15}$

Again, these results apply even with a perfectly-inelastic supply curve; any elasticity of supply makes consumers even worse off.

\section{Example}

A simple functional form for illustrating our results is the Generalized Pareto distribution (GPD), for which

$$
D(p)=k\left(1+\frac{\xi(p-\mu)}{\sigma}\right)^{-1 / \xi}
$$

\footnotetext{
${ }^{13}$ Or write $M R(p)=M C \Rightarrow p+D(p) / D^{\prime}(p)=M C$, which determines the equilibrium price as a function of $M C$ so, differentiating with respect to $M C$, we have

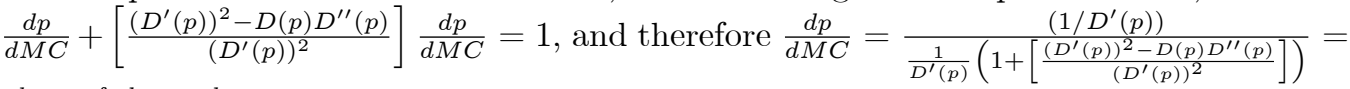
$\frac{\text { slope of demand }}{\text { slope of } M R}$. See Bulow and Pfleiderer (1983); Fabinger and Weyl (2008) describes the general relationship between pass-through and monopoly.

${ }^{14} \mathrm{Or}$, writing $\bar{v}(p)$ for the average value of consumers with values $\geq p$, and $A R$ for average revenue, if the slope of demand is steeper than the slope of MR, then $[\bar{v}(p)-p] \geqslant$ $[A R-M R]$. So since $A R=p$, and $M R=M C$, we have $[\bar{v}(p)-p] \geqslant[p-M C]$, that is, [average $\mathrm{CS}] \geqslant[$ marginal $\mathrm{CS}]$, as required.

${ }^{15}$ From note $13, \frac{d p}{d M C}=\frac{1}{1+\left[\frac{\left(D^{\prime}(p)\right)^{2}-D(p) D^{\prime \prime}(p)}{\left(D^{\prime}(p)\right)^{2}}\right]}$ which exceeds 1 if and only if $D(p) D^{\prime \prime}(p) \geqslant$ $\left(D^{\prime}(p)\right)^{2}$, that is, $D(p)$ is log convex. (The result extends straightforwardly to a Cournot oligopoly: firm $i$, with marginal cost $M C_{i}, i=1, \ldots n$, has equilibrium condition $p+$ $s_{i} D(p) / D^{\prime}(p)=M C_{i}$, in which $s_{i}$ is $i$ 's market share. Summing over all $n$ firms yields $n p+D(p) / D^{\prime}(p)=n \overline{M C}$, in which $\overline{M C}$ is their (unweighted) average cost. So $\frac{d p}{d \overline{M C}}=$ $\frac{1}{1+\left(\frac{1}{n}\right)\left[\frac{\left(D^{\prime}(p)\right)^{2}-D(p) D^{\prime \prime}(p)}{\left(D^{\prime}(p)\right)^{2}}\right]}$ which, as before, exceeds 1 if and only if $D(p)$ is $\log$ convex.) For a very general analysis of pass-through under imperfect competition see Weyl and Fabinger (2009).
} 
Special cases of the GPD are linear demand (when $\xi=-1$ ), constant elasticity (when $\xi \mu-\sigma=0$ and $\xi>0$ ), and log-linear demand (when $\xi \rightarrow$ $0) .{ }^{16}$ With the GPD, $M R(p)=\xi \mu-\sigma+(1-\xi) p$, so the ratio of the slope of the demand curve to the slope of the marginal revenue curve is a constant, $1 /(1-\xi)$. The average consumer surplus, is therefore $\frac{1}{1-\xi}$ times the marginal consumer surplus, $p-M R(p){ }^{17}$

For example, with linear demand $\xi=-1$ and the slope of the marginal revenue curve is twice that of the demand curve, so average consumer surplus is half of marginal consumer surplus (that is, the average buyer's surplus is half of the extra consumer surplus generated by lowering the price enough to sell an additional unit).

For the GPD, therefore, (3) can be rewritten as

$$
C S^{\prime}(p)=S(p) \frac{p-M R(p)}{1-\xi}\left[\frac{S^{\prime}(p)}{S(p)}-\frac{D^{\prime}(p) \xi}{D(p)}\right]
$$

or

$$
C S^{\prime}(p)=\frac{-S^{\prime}(p) D(p)}{(1-\xi) D^{\prime}(p)}+\frac{S(p) \xi}{(1-\xi)}
$$

The best case for price controls is when supply is completely inelastic so $S^{\prime}(p)=0$. In this case, if $\xi<0$ then demand is log-concave and consumer surplus is always increased by a reduction in the price. But if $\xi \rightarrow 0$, as with log-linear demand, then even with inelastic supply the misallocation problem balances the lower prices, and consumer surplus is independent of the price level. For constant-elasticity demand, $1>\xi>0$, any reduction in price below the market-clearing level reduces consumer surplus, as (5) and (6) are both clearly positive.

Obviously, the more sensitive is supply to price the less consumers will gain from any price reduction. Whether they will gain from a small reduction below the market clearing price, where $S(p)=D(p)$, depends on whether $\xi D^{\prime}(p)>S^{\prime}(p)$. So even with linear demand a small restriction on price will only increase consumer surplus if the (absolute value of) demand elasticity is greater than the elasticity of supply.

\footnotetext{
${ }^{16}$ We assume $\xi<1$ so that consumer surplus is finite.

${ }^{17}$ So also a constant-marginal-cost monopolist passes through $1 /(1-\xi)$ of any marginal tax or cost increase, and the ratio of consumer surplus to profits generated by such a monopolist that would set the same price as the price control would be $1:(1-\xi)$.
} 


\section{References}

An, Mark Yuying. "Logconcavity versus Logconvexity: A Complete Characterization", Journal of Economic Theory, 80 (2), 350-369, 1998.

Bagnoli, Mark and Bergstrom, Theodore. "Log-Concave Probability and its Applications", Economic Theory, 26 (2), 445-469, August 2005.

Braeutigam, Ronald R. and Hubbard, R. Glenn. "Natural Gas: The Regulatory Transition", in Weiss, Leonard W. and Klass, Michael W., eds., Regulatory Reform: What Actually Happened. Boston: Little, Brown and Company, 1986.

Bulow, Jeremy and Pfleiderer, Paul. "A Note on the Effect of Cost Changes on Prices", Journal of Political Economy, 91 (1), 182-185, February 1983.

Davis, Lucas and Killian, Lutz. "The Allocative Cost of Price Ceilings in the U.S. Residential Market for Natural Gas", Working Paper, University of Michigan, July 2008.

Fabinger, Michael and E. Glen Weyl. "Pass-Through Determines the Allocation of Surplus under Monopoly", Harvard University Working Paper, October 2008.

Friedman, Milton and Stigler, George. "Roofs or Ceilings? The Current Housing Problem", Popular Essays on Current Problems, 1 (2), 1946.

Glaeser, Edward L. and Luttmer, Erzo F.P. "The Misallocation of Housing Under Rent Control", NBER Working Paper 6620, October 1997.

Glaeser, Edward L. and Luttmer, Erzo F.P. "The Misallocation of Housing Under Rent Control", American Economic Review, 93 (4), 1027-1046, 2003.

Grafton, R. Quentin and Ward, Michael B. "Prices versus Rationing: Marshallian Surplus and Mandatory Water Restrictions", Economic Record, 84, S57-S65, September 2008.

Lott, John R., Jr. "Nontransferable Rents and an Unrecognized Social Cost of Minimum Wage Laws", Journal of Labor Research, XI (4), Fall 1990. 
Luttmer, Erzo F.P. "Does the Minimum Wage Cause Inefficient Rationing?", The B.E. Journal of Economic Analysis and Policy, (Contributions), 7 (1), Article 49, 2007.

MacAvoy, Paul W. and Pindyck, Robert S. The Economics of the Natural Gas Shortage (1960-1980), Amsterdam: North-Holland Publishing Company, 1975.

Palda, Filip. "Some Deadweight Losses from the Minimum Wage: the Cases of Full and Partial Compliance", Labour Economics, 7, 2000.

Prékopa, András, "Logarithmic Concave Measures with Application to Stochastic Programming," Acta Scientiarum Mathematicarum (Szeged), 32, 301-316, 1971.

Spence, A. Michael. "Monopoly, Quality, and Regulation", The Bell Journal of Economics, 6 (2), 417-429, Autumn 1975.

Viscusi, W. Kip, Harrington, Joseph E. and Vernon, John M. Economics of Regulation and Antitrust, 4th Edition, Cambridge, Massachusetts: MIT Press, September 2005.

Weyl, E. Glen and Fabinger, Michal, "Pass-through as an Economic Tool", Harvard University Working Paper, April 2009. 


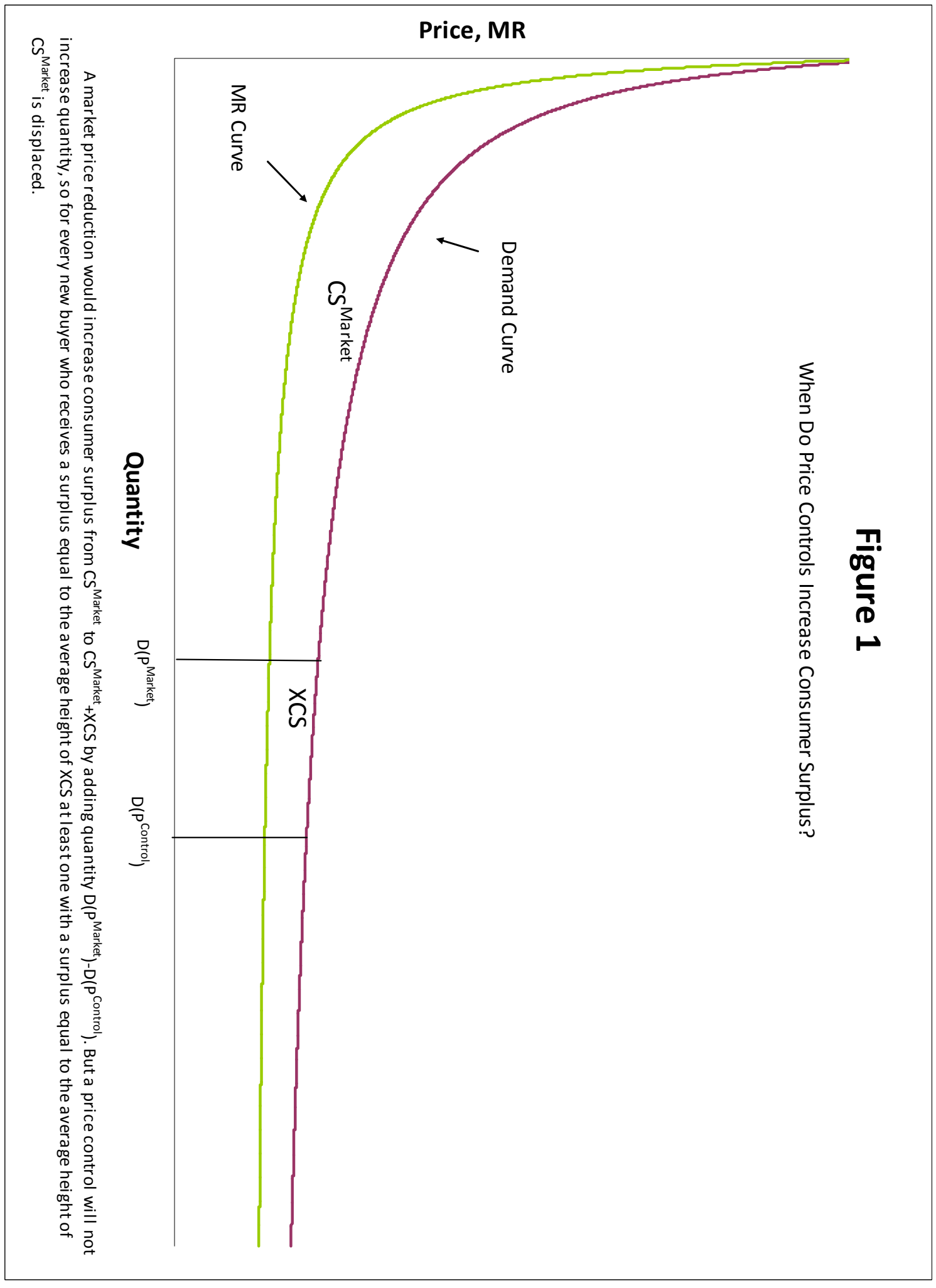

